\title{
Night-time confinement is an unacceptable hospital practice
}

\author{
George Szmukler ${ }^{1}$
}

BJPsych Bulletin (2019) 43, 35-37, doi:10.1192/bjb.2018.82

'King's College London, UK

Correspondence to George Szmukler (george.szmukler@kcl.ac.uk)

First received 8 Jun 2018, final revision 6 Sep 2018, accepted 18 Sep 2018

(C) The Author 2018. This is an Open Access article, distributed under the terms of the Creative Commons Attribution-NonCommercialNoDerivatives licence (http:// creativecommons.org/licenses/by-ncnd/4.0/), which permits noncommercial re-use, distribution, and reproduction in any medium, provided the original work is unaltered and is properly cited. The written permission of Cambridge University Press must be obtained for commercial re-use or in order to create a derivative work.
Summary Night-time confinement, currently imposed as a blanket restriction on all patients on wards in UK high secure hospitals, constitutes an arbitrary restriction of liberty, not being based on any therapeutic purpose for those so restricted, nor serving a need for the protection of others. Its imposition constitutes a form of 'degrading' treatment as well as an unjustified restriction of 'residual' liberty. Persons who are vulnerable, especially those who are involuntarily detained as in this case, are particularly at risk of suffering human rights abuses. A compelling case can be made, based on ethics, law and accepted practice standards, for ruling out night-time confinement as an acceptable measure.

\section{Declaration of interest None.}

Keywords Night-time confinement; secure hospital; degrading treatment; 'residual' liberty.
Night-time confinement (NTC), currently imposed as a blanket restriction on all patients on wards in UK high secure hospitals (see Silva \& Shepherd and Thomson this issue), represents an arbitrary restriction of liberty, not being based on any therapeutic purpose for those so restricted, nor serving a need for the protection of others. Its imposition, I propose, constitutes a form of 'degrading' treatment as well as an unjustified restriction of 'residual' liberty. This is especially troubling when occurring in a hospital, not a prison. Treating patients with respect for their dignity is a fundamental principle of medical care. Persons who are vulnerable, especially those who are detained as in this case, are particularly at risk of suffering human rights abuses.

While there is a duty on those working in the healthcare system to optimise the use of resources, there are 'red lines' limiting what actions can be justified. Locking all patients in their rooms from 9:15 pm to 7:15 am in order to save money on nursing costs crosses such a 'red line'.

Treating patients in this manner cannot be seen as therapeutic or as facilitating recovery; if anything, the reverse. It has been argued that NTC is welcomed by some patients because they feel safer at night. My reaction to this is one of disappointment that wards cannot be made safe using other means. For example, NTC confinement of an individual patient assessed as presenting a risk to others can be acceptable. Further, if patients feel safer when locked in their rooms, they could be offered this option on a consenting, voluntary basis. A valid consent would make the action not a restriction of the person's liberty.

\section{Degrading treatment}

A good case can be made that NTC constitutes a form of 'degrading treatment'.

A definition of 'degrading treatment' can be difficult to establish. Before considering legal aspects, it is helpful to examine, as Waldron ${ }^{1}$ suggests, the ordinary meaning of 'degrading'. The word 'degrading' in everyday language connotes treatment of a person that significantly diminishes their normally accepted rank or status. In this sense, NTC can be seen as degrading the status of 'patient' when set against all other patients (as opposed, say, to prisoners). A further ethical argument is that in NTC patients are being instrumentalised, used as 'means to an end', the 'end' being the saving of money (albeit with the claimed aim of enhancing therapeutic possibilities during the day).

Article 3 of the European Convention on Human Rights $(\mathrm{ECHR})^{2}$ says that 'no one should be subjected to torture or to inhuman or degrading treatment or punishment'. While the European court concedes there is a threshold of severity to be met, the fact that a person is held in control by state agents, for example in detention, will influence that decision. As a rule, the threshold depends on a number of factors including the vulnerability of the person, as well as the duty of care owed by the authorities towards persons held in their care.

The approach of the European court has been to assign the terms 'inhuman' or 'degrading' to an accumulation of particular kinds of practice in particular settings. ${ }^{1}$ The 
meaning of the terms is then read back from the list of particular practices ruled prohibited and identified descriptively. Until a case of NTC, or one relevantly similar to it, is considered, it is not clear whether the European court would regard NTC as constituting 'degrading' treatment.

The Equality and Human Rights Commission (EHRC) ${ }^{3}$ states that 'degrading treatment' means treatment that is extremely humiliating and undignified. Whether treatment reaches a level for such an ascription depends on a number of factors. These include the duration of the treatment, its physical or mental effects, and the vulnerability and health of the victim. In NTC the duration is long-term, perhaps lasting years, and a health problem is the reason for the person being in a hospital. Presumably, the hospital is intended to offer a therapeutic environment for persons with a mental disorder, one that, for example, enhances a sense of agency or self-worth. It is hard to see how NTC encourages, rather than impedes, such progress.

The recognised defence of 'medical necessity" for what may on the surface appear to be degrading treatment, it can be argued, cannot be applicable in NTC: there simply is no medical purpose.

It is commonly stated that the right not to be treated in a degrading way is 'absolute'. The EHRC notes that 'it must never be limited or restricted... For example, a public authority can never use lack of resources as a defence against an accusation that it has treated someone in an inhuman or degrading way. ${ }^{3}$

Waldron poses the question whether treatment can be 'degrading' even if the person subject to it is unconscious of it. ${ }^{1} \mathrm{He}$ proposes that we may judge the treatment as objectively degrading even if the victim accedes to it. A decision in the High Court ${ }^{5}$ supports this contention:

Treatment is capable of being 'degrading' within the meaning of article 3 , whether or not there is awareness on the part of the victim. However unconscious or unaware of ill-treatment a particular patient may be, treatment which has the effect on those who witness it of degrading the individual may come within article 3 [ECHR]. It is enough if judged by the standard of right-thinking bystanders it would be viewed as humiliating or debasing the victim, showing a lack of respect for, or diminishing, his or her human dignity.

This view comports well with the results of a survey of patients and staff concerning their 'agreement' or 'disagreement' with NTC. ${ }^{6}$ This showed that while the majority of the small number of patients (comprising fewer than $50 \%$ of eligible participants) were not in disagreement with NTC, $100 \%$ of staff were.

\section{Deprivation of 'residual liberty'}

Thus far, English law has not recognised the concept of 'residual liberty'. However, the European court following the case of Munjaz $v \mathrm{UK}^{7}$ now does. While the residual liberty of Munjaz was ruled not to have been infringed, the validity of the concept was confirmed by the Court - there can be a further deprivation of one's liberty under Article 5 of the ECHR, even if already detained. The Court held that whether there was a further deprivation of liberty of someone already detained depended on their concrete situation, for example, the type of measure used, and its duration, effects and manner of implementation. In fact, the Court stated, the criteria for a further deprivation 'must apply with greater force' when the person is already detained.

The grounds given for the Court's negative decision in Munjaz offer reasons why NTC, by contrast, might well be considered as a deprivation of residual liberty. The court recognised that Mr Munjaz was secluded when already in a high secure hospital where he was already subjected to greater restrictions on his liberty than a normal mental health patient. However, reasons for a rejection of his claim were: his seclusion was 'to contain severely disturbed behaviour likely to harm others'; the length of the seclusion was 'foremost a matter of clinical judgment'; and great store was placed on 'the manner of implementing the seclusion policy' - the hospital's approach was 'to allow secluded patients the most liberal regime that was compatible with their presentation', and seclusion was being 'flexibly applied'. Behind each reason lay a critical assumption: that the deprivation of liberty served the fundamental purpose of protecting other patients from the harm that might have been caused specifically by Mr Munjaz. The problem with NTC is that its purpose is not therapeutic, nor an individually planned response to the risk of harm to others by the person deprived of their liberty. Furthermore, NTC is clearly not 'the most liberal regime compatible' with the person's presentation, nor is its consistent application for $10 \mathrm{~h}$ each night 'flexible'.

The case for a violation of the patient's ECHR Article 8 right to a 'private life' was also considered. Mr Munjaz argued that the hospital's seclusion policy was not in accordance with the law as it lacked the necessary foreseeability and procedural safeguards. The European court affirmed the presumption that those deprived of their liberty will continue to enjoy all of the other fundamental rights and freedoms guaranteed by the Convention. It stated: 'the importance of the notion of personal autonomy to Article 8 and the need for a practical and effective interpretation of private life demands that when a person's personal autonomy is already restricted, greater scrutiny be given to measures which remove the little personal autonomy that is left... [Mr Munjaz's periods of] seclusion must be regarded as additional interferences with the private life of the applicant, which were distinct from the inevitable interference with his private life that arose from his detention in high security conditions'.

NTC offers little evidence of the kind of additional 'greater scrutiny' demanded by the court. Furthermore, the court stated that any potential breach of Article 8 must be in accordance with the law requiring the impugned measure both to have some basis in domestic law and to be compatible with the rule of law consistent with the object and purpose of Article 8. 'The law must thus be adequately accessible and foreseeable, that is, formulated with sufficient precision to enable the individual - if need be with appropriate advice - to regulate his conduct'. In NTC, on the other hand, the patient's conduct is irrelevant to the deprivation of liberty and thus represents 'arbitrary interference'.

I suggest that NTC would be very unlikely to meet criteria for a lawful restriction of persons' residual liberty or interference with their private life. 


\section{Mental Health Act Code of Practice 2015}

NTC is furthermore inconsistent with 'guiding principles' expressed in Chapter 1 of the Mental Health Act Code of Practice (MHA CoP) $2015^{8}$ - 'the least restrictive option and maximising independence'; 'respect and dignity'; 'purpose and effectiveness... clear therapeutic aims, promote recovery....'

The MHA CoP (26.7) states that restrictive interventions, when required, 'should be planned, evidence based, lawful, in the patient's interests, proportionate and dignified'.

And later:

26.20 ... service providers should avoid blanket restrictions that apply to all patients; interventions should always be individualised, and subject to discussion and review by the whole clinical team. The individual's consent to the intervention should always be sought where the individual has capacity to consent or refuse the intervention, even if a refusal may be overridden...

Under the section entitled 'Respecting human rights':

26.45 Any use of restrictive interventions must be compliant with the Human Rights Act 1998 (HRA), which gives effect in the UK to certain rights and freedoms guaranteed under the European Convention on Human Rights (ECHR).

26.47 No restrictive intervention should be used unless it is medically necessary to do so in all the circumstances of the case. Action that is not medically necessary may well breach a patient's rights under article 3 , which prohibits inhuman or degrading treatment.

26.48 Article 8 of the ECHR protects the right to respect for private and family life. A restrictive intervention that does not meet the minimum level of severity for article 3 may nevertheless breach a patient's article 8 rights if it has a sufficiently adverse effect on the patient's private life, including their moral and physical integrity.

These statements are clearly relevant to the earlier discussion.

I note 26.105 '... Seclusion does not include locking people in their rooms at night in accordance with the High Security Psychiatric Services (Arrangements for Safety and Security) Directions 2013'. Locking patients in their rooms at night is not seclusion; seclusion is justified by clinical considerations of the risk of harm to the patient or to others.
Locking all patients on a ward in their rooms at night as a money-saving measure involves no therapeutic purpose.

\section{Conclusion}

A case, based on ethics, law and accepted practice standards, for ruling out NTC as an acceptable measure is compelling. It should cease as soon as possible.

\section{Acknowledgements}

I thank to fellow members of the Special Committee on Human Rights of the Royal College of Psychiatrists for their helpful comments on the manuscript.

\section{About the author}

George Szmukler is Emeritus Professor of Psychiatry and Society at the Institute of Psychiatry, Psychology and Neuroscience, King's College London, UK.

\section{References}

1 Waldron J. Inhuman and degrading treatment: the words themselves (The Coxford Lecture). Can J Law Jurisprud 2010; 23: 269-86.

2 Council of Europe. European Convention on Human Rights 1950 (https:// www.echr.coe.int/Documents/Convention_ENG.pdf).

3 Equality and Human Rights Commission. Article 3: Freedom from Torture and Inhuman or Degrading Treatment (https://www.equalityhumanrights. com/en/human-rights-act/article-3-freedom-torture-and-inhuman-ordegrading-treatment).

4 Herzczegefalvy v Austria (1992) 10533/83 ECHR 58.

5 Burke R (on the application of) v The General Medical Council Rev 1 [2004] EWHC 1879.

6 Chu S, McNeill K, Wright KM, Hague A, Wilkins T. The impact of a night confinement policy on patients in a UK high secure inpatient mental health service. J Forensic Pract 2015; 17: 21-30.

7 Munjaz v UK (2012) 2913/06 ECHR 1704.

8 Department of Health. Mental Health Act 1983: Code of Practice. TSO, 2015.

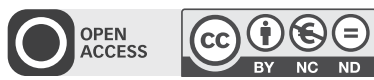

